\title{
Air-water flow in a vertical pipe: experimental study of air bubbles in the vicinity of the wall
}

\author{
M. N. Descamps · R. V. A. Oliemans • \\ G. Ooms · R. F. Mudde
}

Received: 15 August 2007/Revised: 9 January 2008/Accepted: 13 February 2008/Published online: 10 March 2008

(C) The Author(s) 2008

\begin{abstract}
This study deals with the influence of bubbles on a vertical air-water pipe flow, for gas-lift applications. The effect of changing the bubble size is of particular interest as it has been shown to affect the pressure drop over the pipe. Local measurements on the bubbles characteristics in the wall region were performed, using standard techniques, such as high-speed video recording and optical fibre probe, and more specific techniques, such as two-phase hot film anemometry for the wall shear stress and conductivity measurement for the thickness of the liquid film at the wall. The injection of macroscopic air bubbles in a pipe flow was shown to increase the wall shear stress. Bubbles travelling close to the wall create a periodic perturbation. The injection of small bubbles amplifies this effect, because they tend to move in the wall region; hence, more bubbles are travelling close to the wall. A simple analysis based on a two-fluid set of equations emphasised the importance of the local gas fraction fluctuations on the wall shear stress.
\end{abstract}

M. N. Descamps · R. V. A. Oliemans - R. F. Mudde

J.M. Burgerscentrum for Fluid Mechanics,

Delft University of Technology, Multi-Scale Physics,

Prins Bernhardlann 6, 2628 BW Delft, The Netherlands

M. N. Descamps $(\square)$

LEGI, BP53, 38041 Grenoble, France

e-mail: michael.descamps@hmg.inpg.fr

G. Ooms

J.M. Burgerscentrum for Fluid Mechanics,

Delft University of Technology,

Laboratory for Aero- and Hydrodynamics, Mekelweg 2,

2628 CD Delft, The Netherlands

\section{Introduction}

It is well known that bubbles can have a significant effect on the wall drag in turbulent flows. In the past decades many experimental studies have demonstrated that microbubbles are efficient in reducing the skin friction up to $80 \%$ (Madavan et al. 1984). Such studies were motivated by the applications to ships and pipelines (McCormick and Bhattacharyya 1973). In practice it is difficult to create microbubbles and maintain them in the turbulent boundary layer, but small bubbles of a few millimetre dimensions can also reduce the wall drag, as reviewed in Murai et al. (2007). However, for some conditions, the presence of bubbles might increase the wall drag as well. The exact mechanisms by which the wall shear stress is affected by the presence of bubbles are still not understood. In Lu et al. (2005) direct numerical simulations of a bubbly channel flow show that bubbles travelling close to the wall can increase the drag depending on their deformability and their motion with respect to the wall. More deformable bubbles lead to reduction of drag by suppressing the streamwise vorticity. Also by using direct numerical simulations, Ferrante and Elghobashi (2004) point out the existence of a local divergence of the fluid velocity due to the bubble presence, which displaces the vortical structures away from the wall and, in turn, reduces the skin friction. By measuring drag on smooth and rough walls, van den Berg et al. (2007) attribute the drag reduction or increase to a boundary layer effect.

On the other hand, in vertical air-water upward flow, small bubbles, up to a few millimetres, have been shown to reduce the pressure gradient more effectively than larger bubbles, typically larger than $5 \mathrm{~mm}$ (Guet et al. 2003). This is of interest for the gas-lift technique, by which gas bubbles are injected at the bottom of a pipe where a liquid 
is flowing, in order to reduce the gravitational pressure drop. The liquid production is then increased. In gas-liquid vertical bubbly flow the pressure gradient is usually dominated by the gravitational head of the column. Hence, the effect of the gas bubbles on the drag may not be visible for air-water flow at moderate Reynolds number.

However, the frictional component of the pressure drop can become more important when parameters such as the liquid velocity or viscosity are changed. The size of the injected bubbles can then play a role. This situation is relevant for the application of the gas-lift technique to oil production. In this case, both oil and water are flowing in a vertical pipe, and gas is injected to decrease the gravitational pressure drop. We consider the case where oil and water flow as a dispersion, which can be seen as a single liquid phase with its specific properties such as density and viscosity. Previous studies have emphasised the importance of the phase inversion, by which the phase that is dispersed as droplets becomes the continuous phase, and vice-versa (Ioannou et al. 2005; Piela et al. 2006). At the phase inversion the effective viscosity of the oil-water mixture may be several orders of magnitude higher than the oil or water viscosity. It has been shown that introducing gas in a flow of oil and water close to the phase inversion point does not necessarily lead to a reduction in pressure drop: actually it can even increase the pressure drop (Descamps et al. 2006, 2007). A possible explanation is that in such conditions, the wall shear stress induced by the bubbles does affect the total pressure drop.

Therefore, the purpose of this study is to investigate the influence of bubbles on the wall shear stress, for a flow of air and water in a vertical pipe. The wall shear stress is measured via hot film anemometry. The use of water instead of oil and water is related to the non-applicability of hot film anemometry to oil-water flows. Additional measurement of the bubble characteristics, such as bubble size, distance to the pipe wall, is also performed to understand the mechanisms involved.

In Sect. 2 the experimental setup and general measurement techniques are presented. The use of hot film anemometry for bubbly flow requires special care, as described in Sect. 3. A promising technique for measuring the thickness of the liquid layer at the wall is presented in Sect. 4. The results are found in Sect. 5: first general measurements of pressure gradients and gas characteristics are presented, then more specifically the bubble-water interaction in the wall region is investigated. The results obtained are discussed in Sect. 6, with particular focus on the correlation between the bubble passage and the wall shear stress evolution. A simple analytical formulation allows to qualitatively describe the effect of bubbles on the wall shear stress.

\section{Experimental set up}

The experiments were carried out in a vertical pipe loop. The loop was approximately $7 \mathrm{~m}$ high with an internal pipe diameter of $50 \mathrm{~mm}$ and was operated in the turbulent flow regime. The pipes were made out of transparent perspex and PVC. Air was injected from the bottom and separated at the top via a gas-liquid separator (Fig. 1).

Two types of gas injector were used: the porous ring injector, creating small bubbles, and the nozzle injector, creating larger bubbles. An example of the different gas fraction distributions obtained by changing the injector is shown later (Fig. 7). The liquid flow rate could be created by gas injection only (natural convection) or by a centrifugal pump (forced convection). The fluids used were air and tap water.

A differential pressure transducer was placed in the test section part of the loop, with $\Delta h=2 \mathrm{~m}$ between the two points. The pressure measurements were accurate with a relative uncertainty range of $0.5 \%$. Volumetric flow rates were given by a Coriolis flow meter placed in the downcoming part of the loop, where only water flows.

For qualitative visualisation, a sight glass consisting of a cubic perspex box filled with water was mounted around the pipe. This allowed to take pictures and video recordings

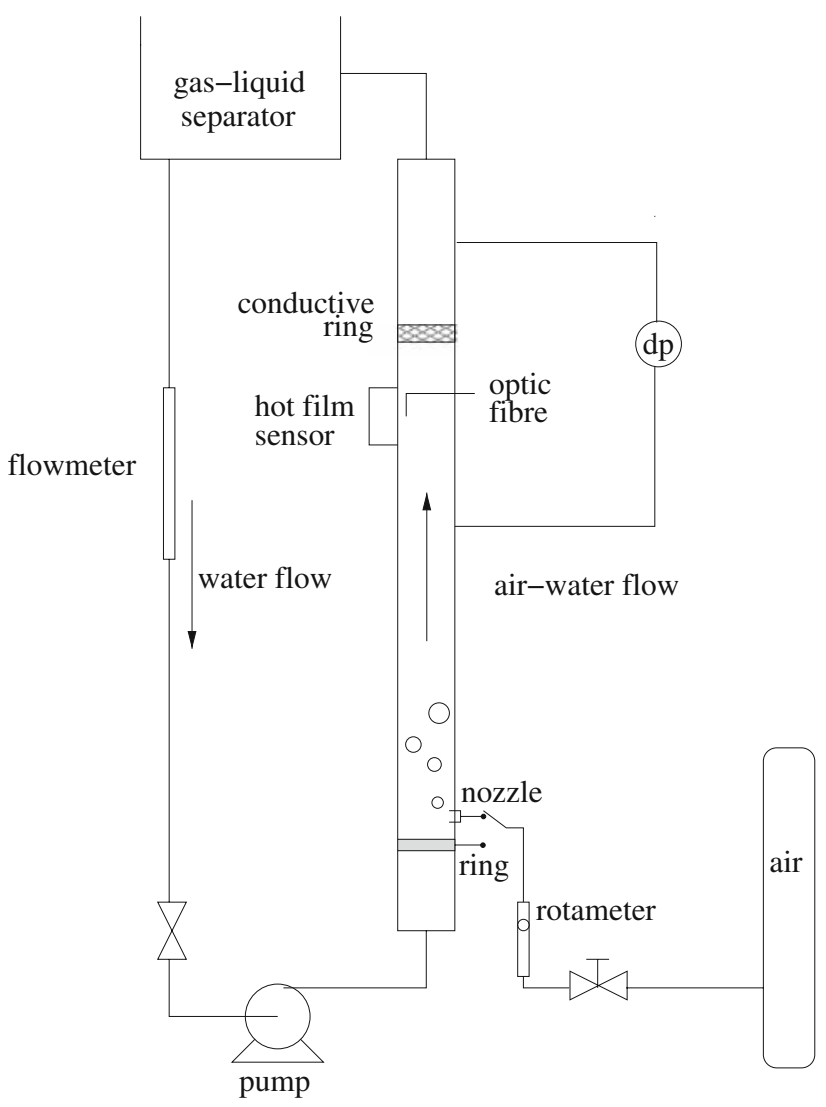

Fig. 1 Sketch of the two-phase flow loop 
with a minimum effect of the pipe curvature on the projected image. An Olympus i-SPEED high-speed camera with a resolution of $800 \times 600$ pixels at 1,000 frames/s was used.

Local measurements of phase fraction and bubble chord length and velocity were performed with an optical fibre probe, which is a standard technique for air-water flows (Julia et al. 2005; Cartellier and Achard 1991). For additional informations about the methods and uncertainties of the technique in the present study, the reader is referred to Descamps et al. (2007). In order to investigate the correlation of wall shear stress with the air bubbles passing nearby, synchronised measurements of the wall shear stress and the local gas fraction were performed. For this purpose, the hot film sensor and the optical fibre probe were mounted at the same height (approximately $4 \mathrm{~m}$ from the pipe bottom), close to the wall. The signals were then sampled using the same analog/digital converter, which allowed for simultaneous measurement of the local void fraction and local wall shear stress with an identical sampling frequency of $100 \mathrm{kHz}$.

The more specific measurement techniques, such as the hot film probe and the conductive ring technique, are described in more detail in the following sections.

\section{Hot film anemometry methodology}

Hot wires and hot films probes have been widely used for velocity measurements in turbulent single-phase flow. It has also been used in two-phase flow with moderate gas holdup, for describing the liquid phase. General characteristics of this technique for two-phase flow can be found in Boyer et al. (2002). In most of the studies the hot film is mounted on a conical probe inserted in the flow, which allows for liquid velocity measurements inside a pipe, away from the near wall region. The resulting signal is a combination of the liquid velocity and the bubbles piercing the probe; hence a careful processing is required.

In the present study, as only the wall shear stress was investigated, the hot film sensor was mounted on the pipe wall. We used a set of DANTEC 55R47 glue-on probes. Each probe was carefully glued on the wall of a piece of pipe, to minimise any step between the wall and the probe. However, the influence of the probe's thickness on the boundary layer could not be assessed. The piece of pipe was installed in the test section of the loop. An AN-1003 anemometry module from A.A. Lab Systems was used to record the probe's answer and condition the signal. The hot film results presented in Sect. 5.4 were repeated with the same hot film sensor, and for different hot film sensors, as it is known that hot film probe characteristics have the tendency to change (Hogsett and Ishii 1997). Eventually, the resistance of the probe increases and its sensitivity decreases. As hot film anemometry relies on heat transfer, the variations of the temperature of the liquid surrounding the film have to be accounted for. Thus, the temperature was recorded to correct its fluctuations.

In situ calibration is needed before each experiment, and recalibration after the experiment. The calibration of the hot film sensor was carried out for a single-phase water flow, using the pressure sensor as a reference measurement. For a single-phase flow in a vertical pipe of diameter $D$, in steady state conditions and neglecting acceleration effects, the total pressure gradient is:

$\frac{d p}{d z}=\frac{4 \tau_{w 0}}{D}+\rho_{l} g$

where $\tau_{w 0}$ is the wall shear stress, and $\rho_{l}$ the liquid density. This can be rewritten as a function of the measured variables:

$\tau_{w 0}^{d p}(U)=\frac{D}{4}\left(\frac{d p}{d z}(U)-\frac{d p}{d z}(U=0)\right)$

where $U$ is the liquid superficial velocity and $\tau_{w 0}^{d p}$ is the wall shear stress deduced from the pressure gradient measurements, on the right hand side of Eq. 2. A relation between the wall shear stress and the heat transfer by convection to the fluid can be found, and the output voltage is correlated via the empirical King's law:

$\tau_{w 0}(U)=K\left(E(U, \theta)^{2}-A^{2}\right)^{3}$

where $E(U, \theta)$ is the hot film sensor signal at the temperature $\theta, A$ and $K$ are some constants. The calibration consisted of measuring the wall shear stress $\tau_{w 0}^{d p}$, for a range of liquid velocities and temperatures, and plotting against the hot film signal $E$ in digital units (Fig. 2).

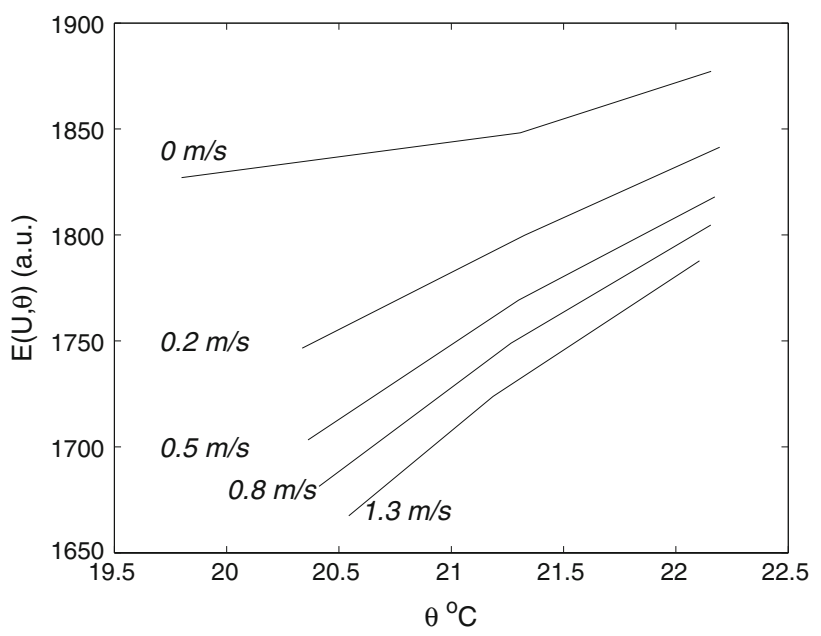

Fig. 2 Calibration of the hot film sensor: effect of temperature on the hot film signal at constant liquid velocity 
The signal given by the hot film probe at a constant liquid velocity and in the range of temperature of the experiments (from $19^{\circ} \mathrm{C}$ to $23^{\circ} \mathrm{C}$ ) is shown in Fig. 2 . Strictly speaking, the signal does not vary linearly with the temperature; however, for the sake of simplicity, the temperature correction was performed by linear interpolation. The error made at this step is supposed to be negligible compared with the other sources of error related to the hot film measurements, as seen later. Once the signals are corrected at a reference temperature, they are plotted for different liquid velocities (Fig. 3). A curve is then fitted to the data using spline interpolation, which is an alternative method to the calculation of the coefficients in Eq. 3 .

\subsection{Error analysis}

The experimental uncertainties arise from three contributions: the pressure measurements used as a reference, the calibration procedure with the fit to Eq. 3 and the intrinsic error of the hot film sensor.

The calculation of the frictional pressure gradient in Eq. 1 requires an accurate measurement of $\frac{d p}{d z}$, because the friction only accounts for a few percent of the total pressure gradient in the present conditions. Also, it is impossible to get the exact measured value for the hydrostatic head $\rho_{l} g$. The relative uncertainty of the pressure sensor as stated by the manufacturer is $r_{d p}= \pm 0.25 \%$, which gives a maximum absolute pressure uncertainty $\delta d p / d z=25 \mathrm{~Pa} / \mathrm{m}$. From Eq. 2, the maximum uncertainty in deducing the wall shear stress from the pressure measurement is:

$\delta \tau_{w 0}^{d p}=\left(\frac{D}{4} \sqrt{2}\right) \delta d p / d z$

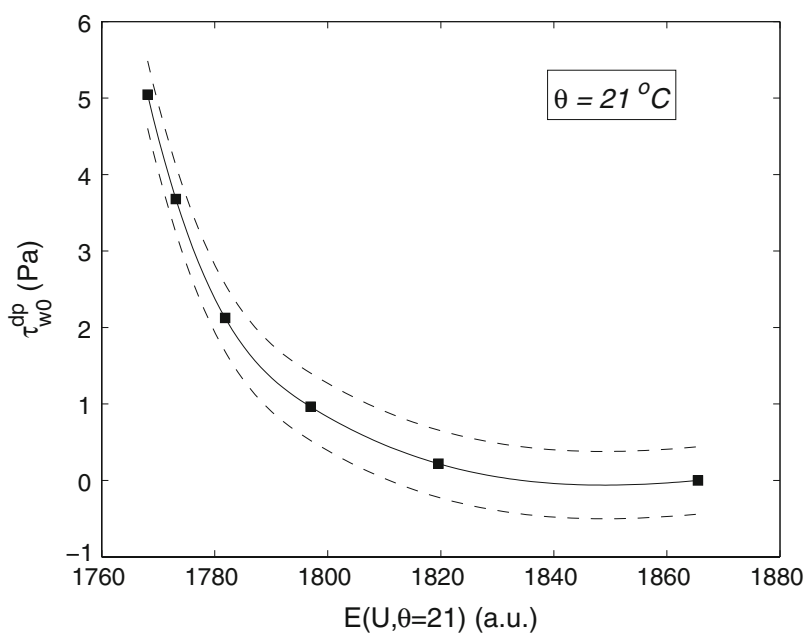

Fig. 3 Calibration of the hot film sensor: corrected hot film signal at a reference temperature of $21^{\circ} \mathrm{C}$. Dashed lines represent the uncertainty range for the fitting curve which gives $\delta \tau_{w 0}^{d p}=0.44 \mathrm{~Pa}$. The wall shear stress presented in Sect. 5.4 is in the order of 1 to 10; hence the relative error on $\tau_{w 0}^{d p}$ can be as high as $50 \%$.

This error then propagates to the calibration curve used to fit the hot film sensor signal. The dashed lines in Fig. 3 stand for the possible calibration curves obtained using $\delta \tau_{w 0}^{d p}=0.44 \mathrm{~Pa}$. As can be seen, for a high shear stress, which corresponds to a higher level of turbulence, the different calibration curves tend to merge, whereas for a low wall shear stress, i.e. low level of turbulence, the different curves are further apart from each other. This shows that accurate wall shear stress measurement in laminar or low turbulence level conditions are not suitable. The hot film calibration procedure introduces an offset of unknown magnitude, but can be supposed to be constant throughout one experiment.

Once a calibration curve has been determined, reproducibility measurements shows that the relative random error of the hot film sensor is about $\pm 5 \%$ for single-phase water flow and $\pm 10 \%$ for gas-liquid flow. This appears to be an acceptable uncertainty, in view of the range of values that is presented in Sect. 5.

Finally, there is an intrinsic uncertainty related to the anemometer system used and the corresponding settings, but this uncertainty is neglected compared with the uncertainties previously discussed. Also the liquid temperature changes affect the signal of the hot film probe. During one experiment, the temperature increase was limited to $2^{\circ} \mathrm{C}$, and with intermediate calibration this effect should disappear.

To summarise, the error analysis shows that the hot films measurements presented here are not expected to compare well with computed data, or absolute data from other experiments. However, this is not an obstacle to the present study as we are interested in comparing the effect of injecting large or small bubbles on the wall shear stress. Such an injection of two types of bubbles was performed within the same experiment and in an alternative sequence (liquid flow, bubbly flow with small bubbles, bubbly flow with large bubbles) to eliminate any hysteresis effect or shift of the hot film probe sensor. So for comparison purposes, the systematic error can be suppressed and the relative uncertainty on the wall drag is taken as $10 \%$. In this respect, the results shown in Sect. 5 will be meaningful as far as the influence of the bubble size is concerned.

\section{Measurement of the liquid film at the wall for air-water flow}

Conductivity measurements are valuable for local discrimination of air and water. In this section it will be shown that it is also possible to get information on the thickness of 
the liquid "film" wetting the wall for an air-water flow. This film corresponds to the distance between the wall and the closest bubble passing at that particular position. It is of interest to measure the averaged and the time-dependent evolution of the liquid film, for different types of bubbles, as it may have some influence on the wall shear stress.

The principle of measurement is based on the wire-mesh technique, frequently used for characterisation of air-water flows (Prasser et al. 2005). The wire mesh sensor was adapted by Belt (2007). A complete description of the technique and validation can be found in Belt (2007), so only details about the calibration procedure are given here.

The probe consists of a conductive ring flush mounted on the inside of the pipe and grounded. The conductivity is measured between the ring and 32 points distributed in the angular direction around the pipe section and connected to an electrical circuit (Fig. 4). The transmitting voltage is a rectangular voltage of amplitude $5 \mathrm{~V}$, and the maximum measuring rate is $5 \mathrm{kHz}$.

The calibration was performed in stagnant conditions: no flow was imposed. For calibrating the device, some PVC cylinders of known diameters were placed in the measurement section, leaving a gap with the pipe wall. Once filled with water, a water film of known thickness was created. The conductivity $\tilde{\sigma}(u=0, \theta)$ given by the ring at each angular position $\theta$ for different film thicknesses was used as a calibration curve. Note that $\tilde{\sigma}(u=0, \theta)$ is scaled such that $\tilde{\sigma}(u=0, \theta)=1$ for the the pipe full of water $\left(d_{\text {film }}=25 \mathrm{~mm}\right)$. Hence 32 calibration curves were defined. In Fig. 5 an example of a calibration curve is shown.

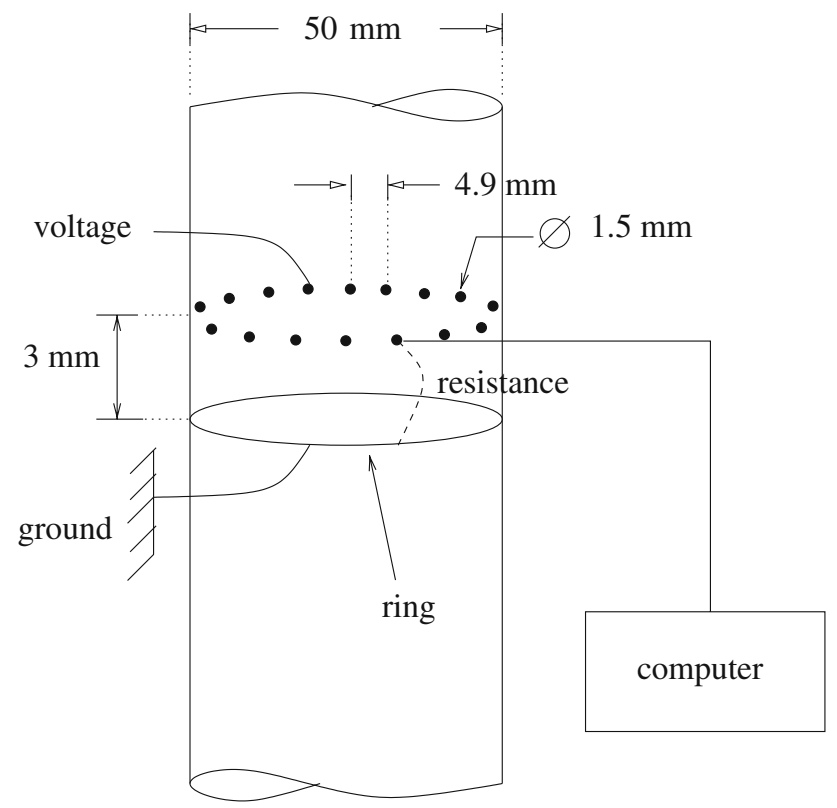

Fig. 4 Conductive ring device for the measurement of the liquid film at the wall in an air-water bubbly flow

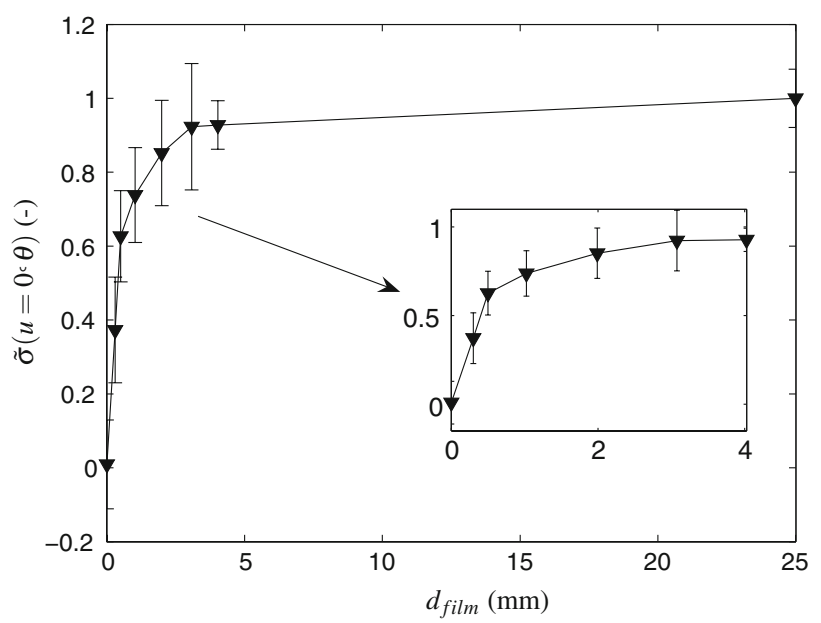

Fig. 5 Example of calibration of the conductive ring for film thickness measurement, at position $\theta$ : conductivity (normalised by full water conductivity) in arbitrary units as a function of the film thickness

It can be seen that for a film thickness larger than 5-10 mm, a small change in the measured conductivity results in a large error in the estimation of the thickness, which can be attributed to a saturation of the signal. This does not limit the use of this technique as we are only interested by local effects at the wall, so a film thickness of more than $10 \mathrm{~mm}$ is out of the scope. Therefore, in the signal processing, a threshold in the signal level is defined above which the film thickness is set to $25 \mathrm{~mm}$, which corresponds to the case of the pipe full of water. This reduces the noise without altering the data of interest. For a thickness smaller than $5 \mathrm{~mm}$, the accuracy of the technique is good, the absolute uncertainty in the film measurement is in the order of $0.2 \mathrm{~mm}$. In pipe flow conditions, the conductivity for pure water $\sigma_{w}(u, \theta)$ is first determined for a a range of liquid velocity $u$ at each position $\theta$. For air-water bubbly flow, the conductivity $\sigma_{\mathrm{aw}}(u, \theta)$ is then divided by $\sigma_{w}(u, \theta)$ to obtain the scaled conductivity $\tilde{\sigma}_{\text {aw }}(u)$ :

$\tilde{\sigma}_{\text {aw }}(u, \theta)=\frac{\sigma_{\mathrm{aw}}(u, \theta)}{\sigma_{w}(u, \theta)}$

It is then assumed that the calibration function $d_{\text {film }}(u=$ $0, \theta)=f(\tilde{\sigma}(0, \theta))$ of Fig. 5 is still valid, from which the film thickness is deduced: $d_{f i l m}(u, \theta)=f\left(\tilde{\sigma}_{\mathrm{aw}}(u, \theta)\right)$. However, it should be noted that the calibration is performed at a constant liquid film thickness around the section, whereas in the case of bubbly flow, the film thickness is non-uniform and depends on the position of the bubbles with respect to the 32 conductive points. The signal will then differ whether the bubble is located between two conductive points or just facing one conductive point. This nonlinear effect is greater as the bubble size is small with respect to the interpoint distance, which is $4.9 \mathrm{~mm}$ (see Fig. 4). In the present study, the bubble size is of the order 
of the interpoint distance, so the position of the bubble with respect to the conductive points is believed to have some minor importance, although it could not be quantified. Therefore, this effect was neglected in the measurement procedure.

For preliminary validation, the case of isolated bubbles travelling close to the wall was studied. In Fig. 6 the evolution of the film thickness is shown. The velocity of the bubble was approximately $0.2 \mathrm{~m} / \mathrm{s}$ and the sampling frequency was $100 \mathrm{~Hz}$.

In Fig. 6a, the liquid film is represented as a function of time, at the angular position $\theta$ at which the bubbles are passing. As expected the liquid layer decreases when the bubble passes the sensor, in this case the film is about $4 \mathrm{~mm}$. In Fig. 6b, the spatial evolution of the film thickness is represented at the moment the bubble passes at $\theta=273^{\circ}$. The film thickness is then $25 \mathrm{~mm}$ at every position except around $\theta=273^{\circ}$, where the film is about $4 \mathrm{~mm}$, revealing the presence of the bubble.

So, despite some limitations, the film measurement technique using a conductive ring is valuable for measuring the thickness of the water film between the wall and the bubbles, in air-water bubbly flows. For the results presented in Sect. 5.3, a sampling frequency of $1,000 \mathrm{~Hz}$ over a sampling time of $5 \mathrm{~s}$ has been used.

\section{Experimental results}

\subsection{Void fraction, bubble size and velocity}

In Fig. 7 the mean gas fraction is plotted as a function of the normalised distance to the pipe axis, for the two types of injectors used in this study.
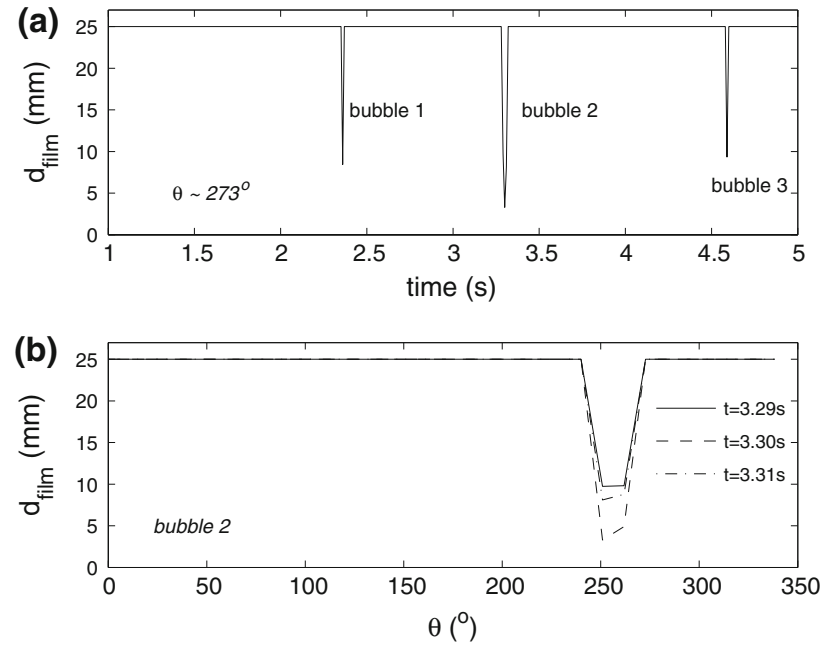

Fig. 6 Example of film thickness measurement for isolated bubbles in stagnant conditions: a temporal evolution of the film thickness at $\theta=273^{\circ}$, b spatial evolution of the film thickness at the passage of a bubble
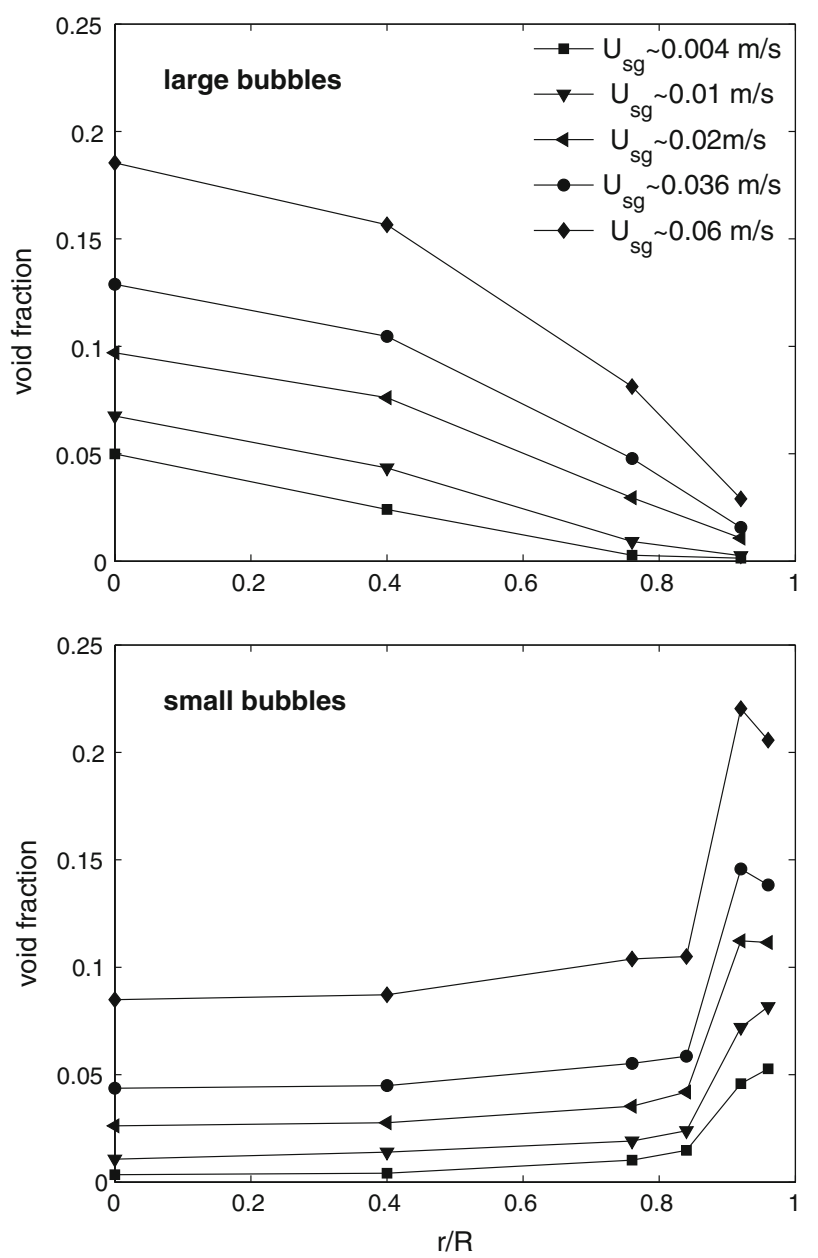

Fig. 7 Radial profile of the gas fraction for large and small bubbles, at $U_{\mathrm{sl}}=0.86 \mathrm{~m} / \mathrm{s}$

The liquid superficial velocity is kept constant and the gas superficial velocity is changed. The radial void fraction profile depends on the size of the injected bubbles: large injected bubbles cluster in the core of the pipe (Fig. 7, top), whereas small injected bubbles accumulate at the wall (Fig. 7, bottom). The migration of bubbles in radial direction depending on their size is determined by the evolution of the bubble lift force with respect to bubble size in a shear flow (Tomiyama et al. 2002). The radial distribution of the bubbles has some influence on the liquid velocity profile in the transverse direction, but, because different mechanisms play a role for different bubble size, it may be expected that no universal expression for the velocity profile may be derived for bubbly flows.

As for the bubble size and velocity, the main differences between the two injectors can be seen from Fig. 8. In this figure, the bubble velocity is plotted as a function of the bubble size for a range of conditions, including: liquid superficial velocity between 0.4 and $1.00 \mathrm{~m} / \mathrm{s}$, gas superficial velocity from 0.003 to $0.06 \mathrm{~m} / \mathrm{s}$ and a radial distance to the pipe axis from 0 (pipe core) to 0.96 (pipe wall). For 
each of these cases, a number of bubbles are detected for both injectors, and then the bubble size and velocity is averaged.

Figure 8 shows that the nozzle injector produces a wide variety of bubbles, from small (3 $\mathrm{mm}$ in chord) to large (over $10 \mathrm{~mm}$ ). On the other hand the ring injector produces homogeneous small bubbles ( $3 \mathrm{~mm}$ in chord) for all conditions previously mentioned, which means that for this injector the bubble size is independent of the radial distance to the wall (homogeneous distribution) and of the liquid velocity. This suggests that for this injector, the bubble size is not determined by the turbulence intensity of the flow, but by the inlet conditions. Qualitative information about the shape of the bubbles is given by the high speed camera. We found that the bubbles are ellipsoidal for a chord up to 4-5 $\mathrm{mm}$ and spherical-cap beyond this chord. So the bubbles produced by the ring injector are ellipsoidal. For high gas injection rates, leading to gas volume fraction higher than $10 \%$, slug flow with large Taylor bubbles can be generated.

\subsection{Pressure measurements}

For a flow of air and water, the difference in pressure gradients over the pipe obtained by changing the gas injector can be seen in Fig. 9. (The $z$ coordinate corresponds to the pipe axis and is pointing in the same direction as gravity for this figure).

The air-water pressure gradient is lower than the single phase water pressure gradient. For a given gas superficial velocity, injecting small bubbles rather than large bubbles results in an additional reduction of the pressure gradient. In terms of gas-lift, the efficiency of injecting gas can be quantified in the form of a ratio:

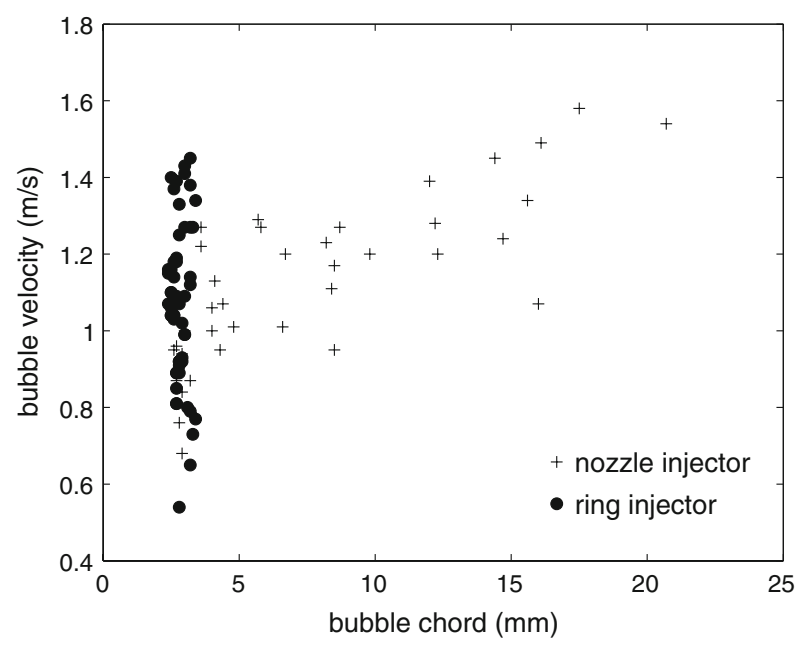

Fig. 8 Bubble size and velocity for a range of conditions

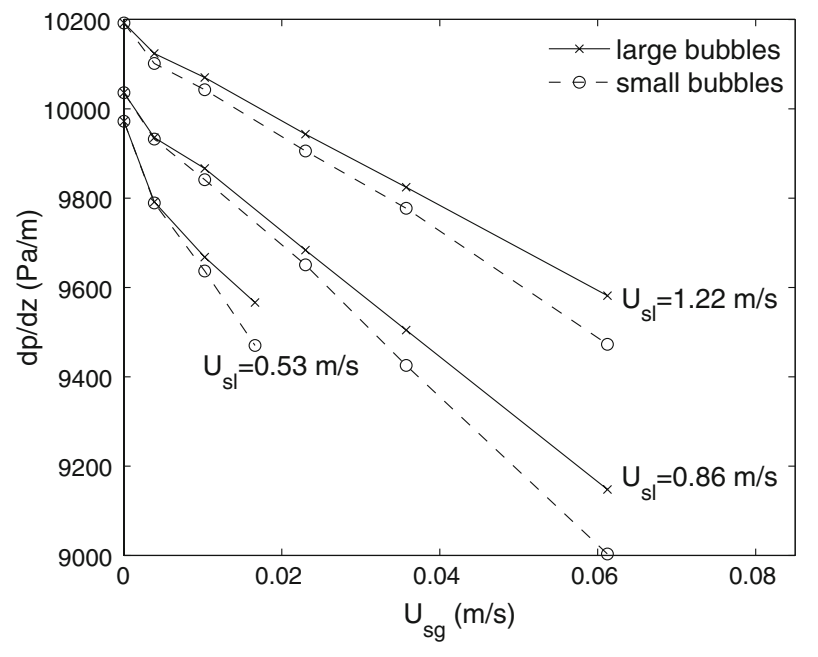

Fig. 9 Air-water pressure drop as a function of the gas superficial velocity

$\Delta P=\frac{\frac{d p}{d z_{\text {liquid }}}-\frac{d p}{d z_{\text {gas-liquid }}}}{\frac{d p}{d z_{\text {liquid }}}}$

where $\Delta P$ is a normalised reduction in pressure drop over the pipe. In Fig. 10, a comparison between $\Delta P_{\text {nozzle }}$ (large bubbles) and $\Delta P_{\text {ring }}$ (small bubbles) is made for a range of conditions.

In Fig 10, the liquid Reynolds number $\operatorname{Re}_{l}=U_{\mathrm{sl}} D / v_{l}$ varies from 25,000 to 75,000, and the gas Reynolds number $R e_{g}=U_{\mathrm{sg}} D / v_{g}$ varies from approximately 15 to 400 , where $U_{\mathrm{sl}}$ and $U_{\mathrm{sg}}$ are the liquid and gas superficial velocities, respectively. In the case of air-water flow, the efficiency of the gas-lift technique can be improved by $20 \%$ when using small bubbles, which was reported in Guet (2004).

\subsection{Bubbles close to the wall}

Zaruba et al. (2007) reported two types of motion for isolated bubbles in the vicinity of a wall, in a gas-liquid channel flow: a bouncing and a sliding motion. The bouncing motion for a single bubble could be theoretically predicted considering the drag, lift and deformation forces. Our experiments confirmed the bouncing motion of the bubbles on the wall for a bubbly flow, as shown in Fig. 11. Here, it should be noted that stricto sensu, there is no bouncing with the pipe wall as there is always a film of water between the bubble and the wall, as shown subsequently.

In Fig. 11, the trajectory of bubbles has been tracked from a recorded image sequence. Based on the images, the frequency of the oscillatory motion is estimated around $10 \mathrm{~Hz}$, for an amplitude in spanwise direction of 0.06 of the pipe diameter. The liquid Reynolds number is approximately 6,500 , so it is not representative of the 


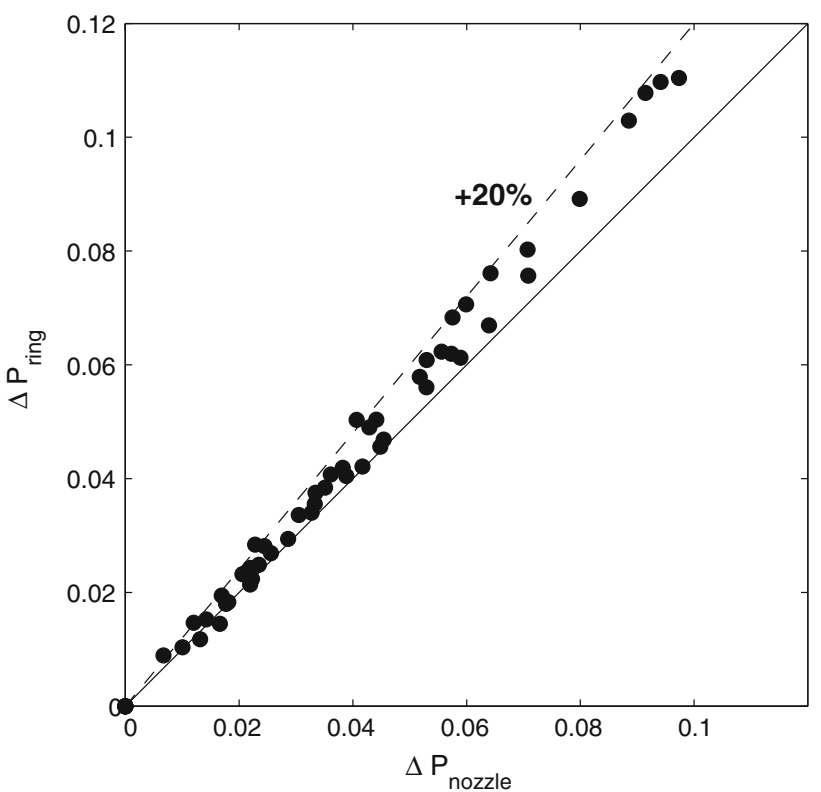

Fig. 10 Comparison of the reduction in pressure drop for large bubbles $\left(\Delta P_{\text {nozzle }}\right)$ and small bubbles $\left(\Delta P_{\text {ring }}\right)$

highly turbulent flow conditions of the next sections. The figure still illustrates the oscillatory motion of the bubbles which also occurs at higher Reynolds number, but with higher frequency and lower amplitude. Furthermore, at a constant location at the wall, the liquid layer fluctuates, due to the passage of the bubbles. In Fig. 12, an example of the temporal evolution of the film thickness is shown for the two types of injectors used.

As mentioned in Sect. 4, the range of detection of the device corresponds to liquid film thicknesses from 0 to $5 \mathrm{~mm}$. The difference between the large bubble injector (nozzle; Fig. 12, top) and the small bubble injector (ring; Fig. 12, bottom) is obvious. The interpretation of the

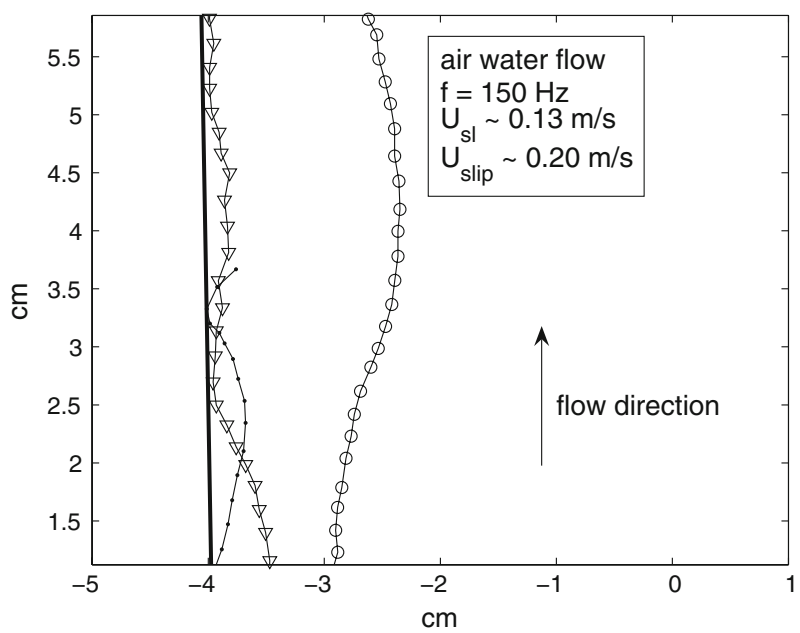

Fig. 11 Example of bubble trajectories in vertical gas-liquid flow. The solid line represents the pipe wall different signals is as follows. The ring injector only produces small bubbles that remain in the wall region so the film thickness fluctuates in a regular way, in comparison with the signal from the large bubble injector. The large bubbles produced by the nozzle injector tend to entrain smaller bubbles in their wake. These smaller bubbles are grouped in a cluster, and some of them migrate to the wall. Hence the signal for the nozzle injector consists of small fluctuations and gaps. The passage of the large bubbles and the following small bubble cluster create the fluctuations, and the region is free of small bubbles until the next large bubble creates the gap.

In Fig. 13 the statistical characteristics of the liquid film thickness are shown: the distribution of the thickness (Fig. 13a) and the evolution of the mean distance of the bubbles close to the wall (Fig. 13b).

It can be observed that within the range of detection, there is an approximate Gaussian distribution of the film thickness around a mean, which represents the mean distance from the wall to the nearest bubbles, for a large number of bubbles. Note that this Gaussian distribution is not to be confused with the location of the gas void fraction peak, as can be demonstrated in Fig. 13a, where the void fraction is "core-peaking". The mean film thickness in the wall region is plotted against the gas inlet conditions, for both injectors, in Fig. 13b. It can be seen that in general, the distance between the pipe wall and the nearest bubbles is between 2 and $3 \mathrm{~mm}$. Furthermore, by looking carefully at the minimum distance between the wall and the bubbles, it is confirmed that there is a bubble-free layer, whose thickness is less than $500 \mu \mathrm{m}$ for all the cases studied. In Sato et al. (1981) this bubble-free layer is estimated to be around $20 \mu \mathrm{m}$. Also, Fig. 13b shows that the bubbles produced by the ring injector travel closer to the wall,
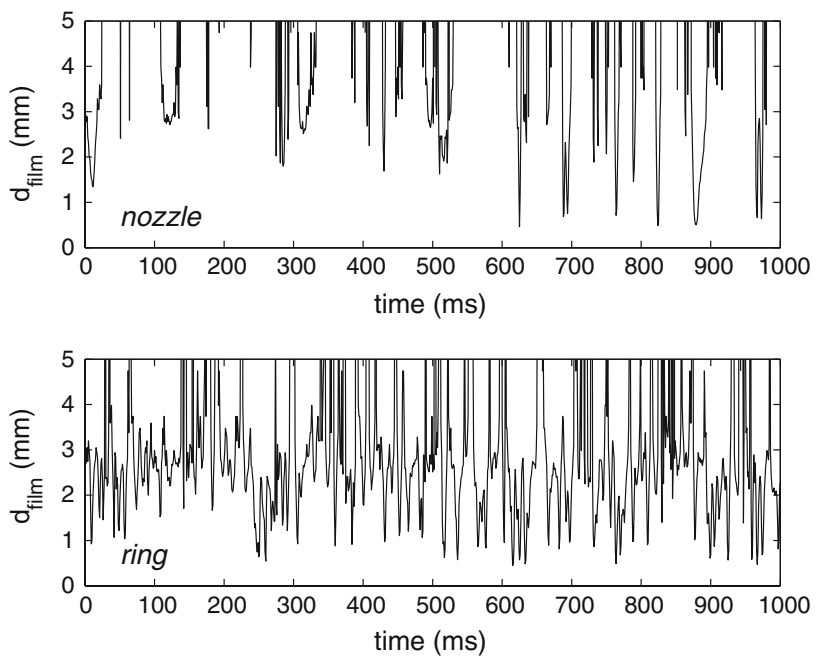

Fig. 12 Example of the time signal of the film thickness at one angular location, at $U_{\mathrm{sl}}=0.86 \mathrm{~m} / \mathrm{s}$ and $U_{\mathrm{sg}}=0.06 \mathrm{~m} / \mathrm{s}$ 

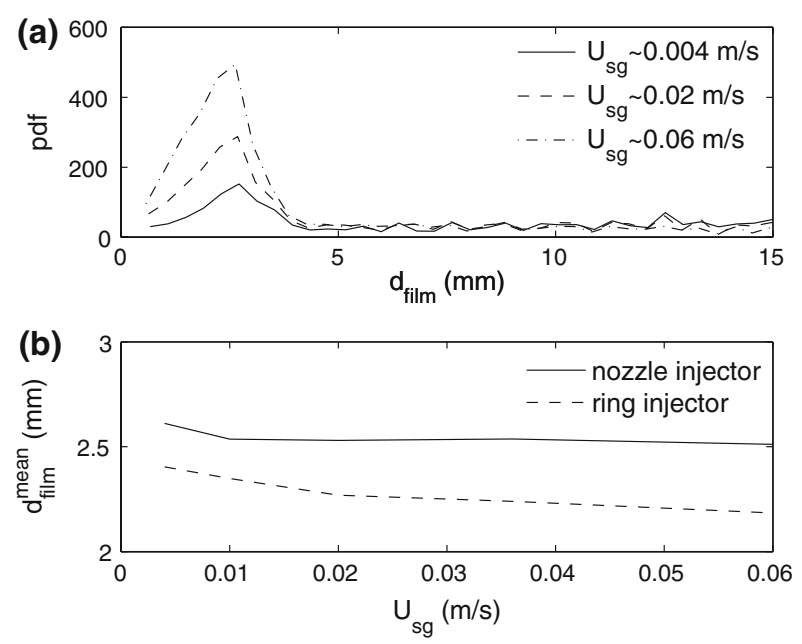

Fig. 13 Liquid film thickness for an air-water flow. a Nozzle injector, probability density function (in arbitrary units) of the liquid film thickness, at $U_{\mathrm{sl}}=1.22 \mathrm{~m} / \mathrm{s}$. b Mean liquid film thickness in the wall region, at $U_{\mathrm{sl}}=1.22 \mathrm{~m} / \mathrm{s}$

compared with the bubbles produced by the nozzle injector. This can be due to the compression of the bubbles against the wall for large void fraction in the wall region. The ring injector leads to a wall peaking void fraction, which means that many (small) bubbles travel in the wall region, interacting with each other, and possibly pushing some bubbles nearer to the wall, thus reducing the liquid layer. For the nozzle injector only occasional small bubbles are generated by break-up of the large bubbles, and in the absence of interaction with other bubbles, the lift force and wall repulsion are the main mechanisms governing the distance between the wall and the bubbles.

The bubbles close to the wall can also be detected using the optical fibre probe. In particular, the bubble interarrival time $t_{\Delta}$, i.e. the time between two successive bubbles passing at a specific location, is of interest as far as the wall drag is concerned. It can be related to the frequency of the possible oscillatory stress at that location. In Fig. 14, an example of the distribution of $t_{\Delta}$ is plotted.

The fibre probe was placed at approximately $2 \mathrm{~mm}$ from the wall $(r / R \approx 0.92)$, which corresponds to the zone where small bubbles travel and may bounce on the wall according to Fig. 13, and the bubbles were detected for $60 \mathrm{~s}$. In Fig. 14, the liquid superficial velocity was $U_{\mathrm{sl}}=0.86 \mathrm{~m} / \mathrm{s}$ and the gas superficial velocity was $U_{\mathrm{sg}} \approx$ $0.06 \mathrm{~m} / \mathrm{s}$. A total of $\mathrm{Nn}=661$ and $\mathrm{Nr}=4813$ bubbles were detected during $60 \mathrm{~s}$ by the probe for the nozzle and ring injector, respectively. The distributions, normalised by $\mathrm{Nn}$ and $\mathrm{Nr}$, are Poisson-like for both injectors, only the time scale differs.

For all the liquid and gas superficial velocities, the distributions are similar. As expected, the ring injector, which produces only small bubbles accumulating in the
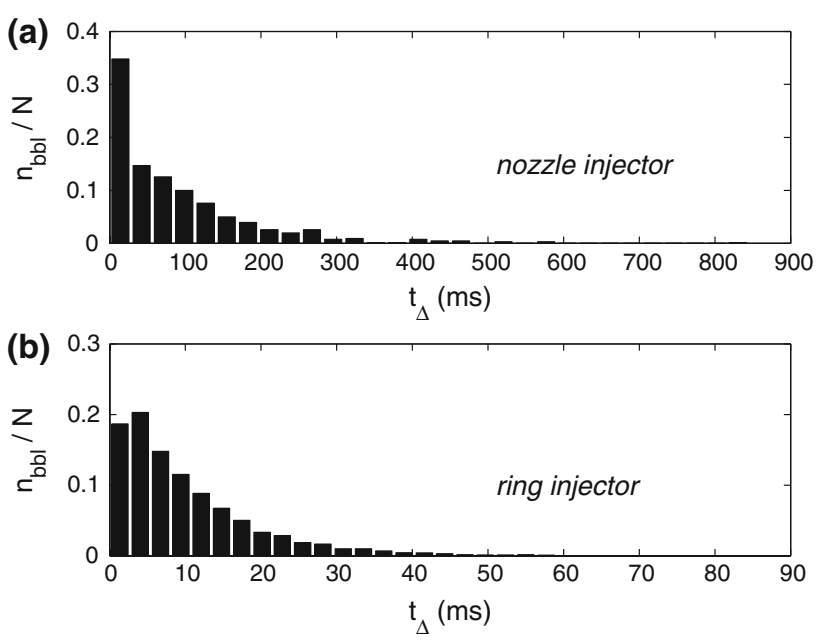

Fig. 14 Distribution of bubble interarrival time, close to the wall

wall region, leads to smaller interarrival times. On the other hand, the nozzle injector mainly produces large bubbles, but turbulent break up also causes small bubbles to be created occasionally, some re-coalescing to form larger bubbles, some remaining small and migrating towards the wall. Hence the interarrival time for the nozzle injector is much larger. To compare these distributions under a range of conditions, it is convenient to define a characteristic interarrival time $t_{99}$ such that:

$\int_{0}^{t_{99}} n\left(t_{\Delta}\right) d t_{\Delta}=0.99 N$

so $t_{99}$ is the time below which $99 \%$ of all the bubble interarrival times fall. A characteristic frequency $f_{99}$ of bubble passage can then be defined as:

$f_{99}=1 / t_{99}$

In Fig. 15, the variation of $f_{99}$ with respect to the local void fraction is plotted. A number of experiments are represented on Fig. 15, with liquid Reynolds number ranging from 10,000 to 50,000 and different gas superficial velocities. It can be seen that, in the wall region (closed symbols) the bubbles produced by the two injectors follow the same trend, with a higher characteristic frequency for a higher local void fraction. The only difference is that the nozzle injector, which produces less number of small bubbles, leads to smaller void fraction at the wall and thus smaller characteristic frequency. So the bubble passage frequency varies approximately linearly with the gas fraction at the wall, irrespective the injector used:

$f_{99} \approx 100 \varepsilon_{a}$ 
For comparison the characteristic frequency of bubbles in the pipe centre differs according to which injector is used (open symbols in Fig. 15). The large bubbles generated by the nozzle injector are further apart from each other than the small bubbles generated by the ring injector. So in the pipe centre, at a constant local void fraction, the nozzle injector leads to a smaller characteristic frequency than the ring injector.

Hence Fig. 15 emphasises the occurrence of a periodicity of bubbles passing close to the wall, independently of the injector chosen, because only small bubbles travel in this region. This periodicity is a function of the local void fraction at the wall, and may influence the wall shear stress.

\subsection{Wall shear stress measurements}

The anemometer measurements were combined with pressure measurements for all gas and liquid superficial velocities. Figure 16 presents the wall shear stress data corresponding to the same experiment as in Fig 9.

As mentioned previously, the relative uncertainty is rather large on this figure and does not allow for a fine interpretation of the curves, for instance regarding the different slopes. But some general trends can be highlighted:

- As the liquid superficial velocity increases, the wall drag increases, which is reflected by the increase in wall shear stress at $U_{\mathrm{sg}}=0$ (single-phase water flow).

- At a constant liquid superficial velocity and increasing the gas superficial velocity, the resulting variation of wall shear stress depends on the type of bubbles injected. Small injected bubbles cause a higher wall shear stress than large injected bubbles. This effect becomes more significant as the gas superficial velocity is increased. (It can be supposed that for low gas superficial velocity, the effect of the injected bubbles on the wall stress is negligible in comparison with the liquid shear, especially as the liquid superficial velocity is increased.)

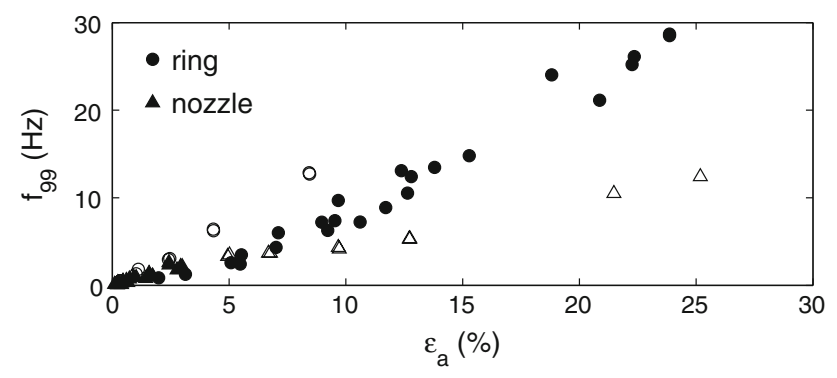

Fig. 15 Characteristic frequency of passing bubbles: close to the wall (closed symbols), at the pipe axis (open symbols)

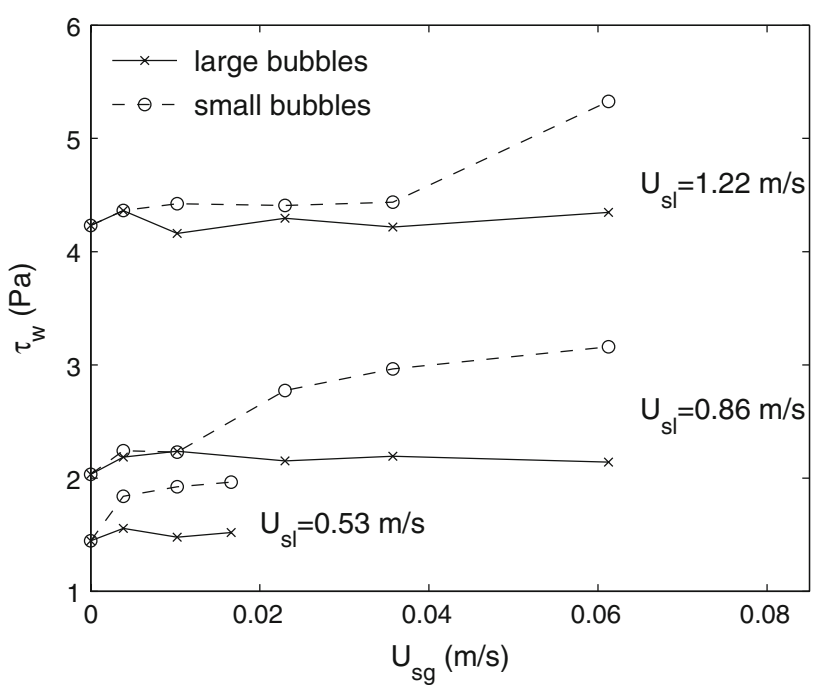

Fig. 16 Air water shear stress at the pipe wall

- It can be seen that the large bubbles do not have a great effect on the wall drag: its value remains more or less the same as the single-phase $\left(U_{\mathrm{sg}}=0\right)$ value. On the contrary, small bubbles tend to increase the wall drag, with increasing gas flow rate.

These conclusions, deduced from the single experiment of Fig. 16, are consistent as they have been reproduced for a number of experiments, even though some scattering occurred in the magnitude of the wall shear stress measured, as explained in Sect. 3. Using a bubble column, Magaud et al. (2001) also showed that the mean wall shear stress was higher in bubbly flow than in single-phase flow. In this work the bubble size was between 2 and $4 \mathrm{~mm}$, and bubbles were homogeneously injected, which is analogous to the conditions created by the ring injector in our study. Furthermore, the amplifying effect of decreasing the liquid velocity (Magaud et al. 2001; Moursali et al. 1995) is also found here: the relative increase in wall shear stress ratio is in the order of $25 \%$ for the largest liquid velocity $U_{\mathrm{sl}}=1.22 \mathrm{~m} / \mathrm{s}$, and in the order of $100 \%$ for the smallest velocity $U_{\mathrm{sl}}=0.53 \mathrm{~m} / \mathrm{s}$. So Fig. 16 is representative of the general tendency of small bubbles travelling close to the wall to increase the drag on the wall by creating perturbations in the liquid velocity. Those perturbations arise from the fluctuations in the wall shear stress $\tau^{\prime}$. In Fig. 17, the relative wall shear stress fluctuations are shown as a function of the gas void fraction.

It can be seen that the fluctuations are higher for a lower liquid velocity, as observed above for the mean shear stress ratio. Furthermore, for small local gas fraction $\varepsilon_{a}$, the fluctuation rate increases with $\varepsilon_{a}$. Moursali et al. (1995) attribute this effect to the velocity perturbations induced by the bubbles sliding along the wall. However, for larger gas fraction, the shear stress fluctuation rate seems to be 


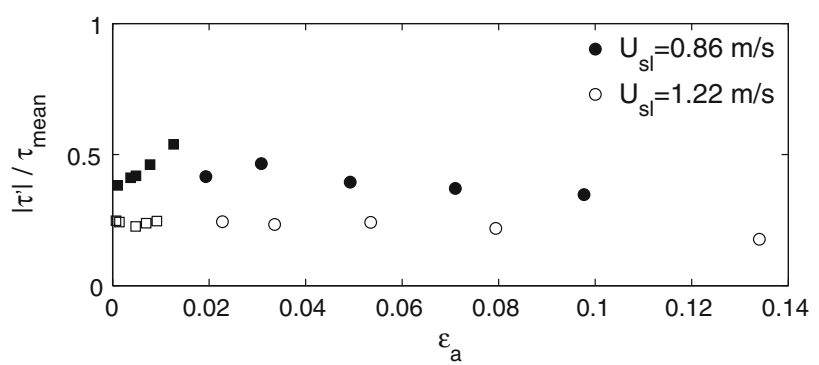

Fig. 17 Wall shear stress fluctuation intensity. Square symbols stand for the bubbles generated by the nozzle injector, circle symbols stand for the bubbles generated by the ring injector

independent of $\varepsilon_{a}$, which is also observed in the experiments of Magaud et al. (2001) and Moursali et al. (1995).

So the previous figures point out the greater influence of the ring injector on the wall shear stress, when compared to the nozzle injector, mainly because of the difference of local void fraction obtained at the wall. This can also be seen on Fig. 18 where a comparison between the wall shear stress for the two types of injector is presented.

In this figure the range of conditions is the same as that of Fig. 10. The relative increase of wall drag when using small bubbles instead of larger bubbles can be as high as $70 \%$. It can be noted also, that in some cases, there is no difference between small and large bubbles. These cases correspond to the lowest gas superficial velocities in Fig. 16: in this range of velocity, the wall shear stress for small and large injected bubbles is more or less the same, especially as the water superficial velocity is increased.

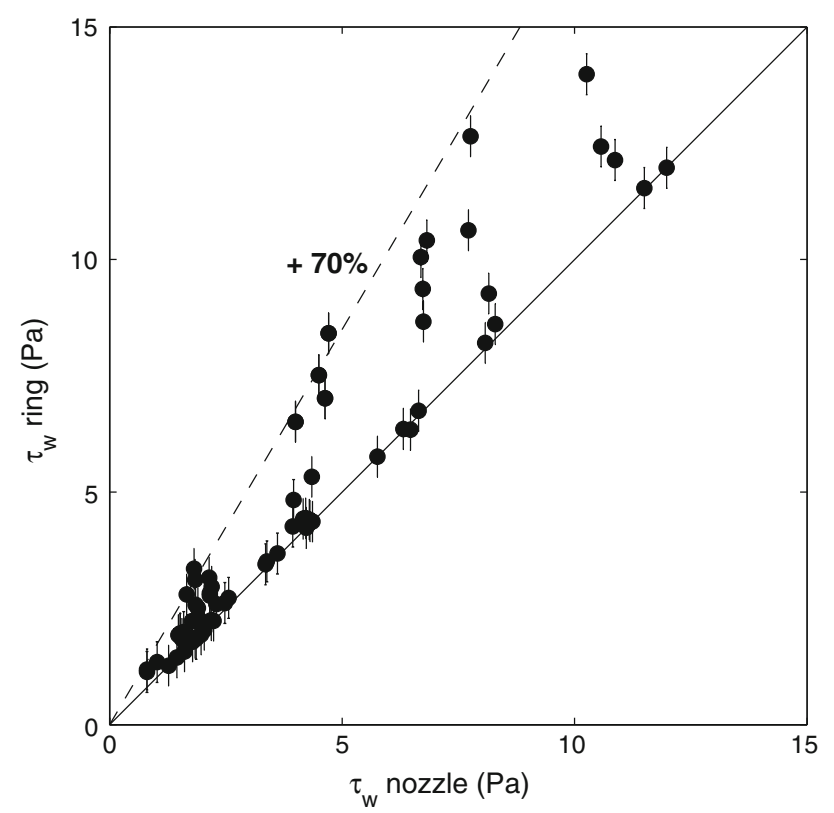

Fig. 18 Comparison of the wall shear stress for large injected bubbles $\left(\tau_{w}\right.$ nozzle) and small injected bubbles ( $\tau_{w}$ ring) at the same conditions
Therefore, the friction contribution to the pressure drop is generally larger when bubbles are smaller than for larger bubbles. However the increase in wall shear stress is in the order of $5 \mathrm{~Pa}$ (Fig. 18), which results in a friction pressure drop of $400 \mathrm{~Pa} / \mathrm{m}$ (equation 1), and the total pressure gradient is in the order of $10,000 \mathrm{~Pa} / \mathrm{m}$ (Fig. 9). So, by using small bubbles, the increase in wall shear stress represents approximately $4 \%$ of the total pressure gradient. The reduction in gravitational pressure drop is still dominant for such conditions and thus, using small bubbles is beneficial for gas-lift applications, because the total pressure gradient can be reduced by using smaller bubbles (Fig. 10).

\section{Parameters affecting the wall shear stress}

In this section we analyse the local effect of bubbles on the wall shear stress via the modification of the turbulent characteristics of the flow.

For a void fraction below a critical value $\varepsilon_{c}$, Lance and Bataille (1991) decompose the turbulent kinetic energy of a uniform bubbly flow in two parts: (1) the grid generated turbulence, or mean liquid velocity turbulence, and (2) the "pseudo-turbulence" or bubble induced turbulence, associated with the motion of non-interacting bubbles. For a void fraction above $\varepsilon_{c}$ the interactions between the bubbles have to be taken into account.

Murai et al. (2007) showed that the instantaneous evolution of the wall shear stress in air-water flows is directly related to the passage of air bubbles. By performing synchronised measurements of wall shear stress and 2D gas void fraction (i.e. a projection of the local volume fraction on the area of the wall shear stress sensor), it was shown that there is a negative correlation between the two signals. For the case of a horizontal channel flow, the friction increases as the front part of the bubble passes through the sensor, and friction decreases at the rear part of the bubbles. In Fig. 19, synchronised measurements of wall shear stress and bubble passage from our experiments are shown.

The wall shear stress $\tau_{w}$ in the figure is normalised by the wall shear stress for single phase flow $\tau_{w 0}$. Superimposed is the processed void fraction, which corresponds to the binary indicator of the gas phase $X_{g}$ at the measurement point: $X_{g}=0$ stands for water, $X_{g}=1$ for gas. It becomes clear that for bubbly flow in a vertical pipe, there is a strong correlation between both quantities. But contrary to the findings of Murai et al. (2007), the correlation is positive. The passage of bubbles is associated with a wall shear stress spike. An example of a wall shear stress spike correlated to a bubble passage is found in Fig. 20. This spike consists of an abrupt increase in wall shear stress at the beginning of the bubble, followed by a less steep decrease at the end of the bubble, that can be seen as a relaxation 

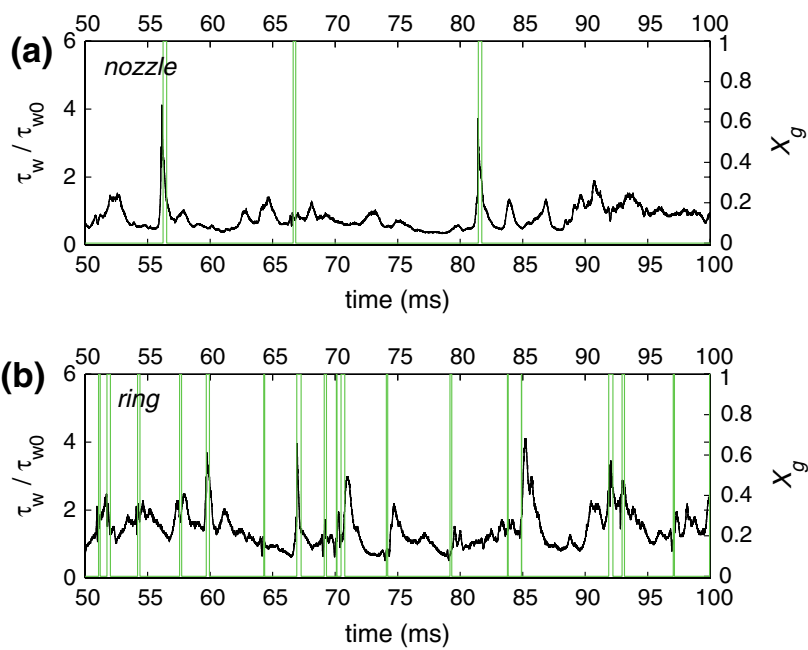

Fig. 19 Example of synchronised measurement of wall shear stress (black line) and gas phase indicator at the wall (light colour)

time before the stress goes back to the bubble-free level of single phase flow. This could be due to the wake of the bubbles.

Note that because of the small axial and radial gap between the optical fibre tip and the hot film element, the bubbles are not simultaneously detected by both devices. The fibre probe is located $1 \mathrm{~mm}$ upstream of the hot wire, so some bubbles interacting with the hot film may not be pierced by the optical probe. Hence, some wall shear stress spikes occur without bubble detection in Fig. 19. Also, turbulent fluctuations due to bursting, or sweeping may cause such spikes, even though no measurement could confirm such an effect.

The use of a ring injector, which causes a higher void fraction at the wall, results in a larger number of wall shear stress spikes, and a higher value of the bubble-free level, because the stress does not have the time to reach the single phase flow value. This explains why the averaged wall shear stress is higher for the ring injector than for the nozzle injector, as was observed in Fig. 18.

Hence these synchronised measurements show that the presence of bubbles in the wall region introduces additional

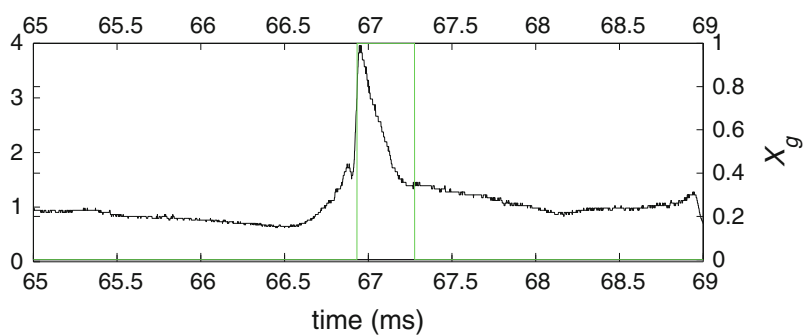

Fig. 20 Synchronised measurement of wall shear stress (black line) and gas phase indicator at the wall (light colour) at the passage of a bubble stresses by creating a sudden increase of the stress and then slowly relaxing to the single-phase value. These additional stresses can be included in Reynolds averaged NavierStokes equations, as done in a single-fluid model by Sato et al. (1981), but in the absence of experimental support. In a recent contribution, Murai et al. (2006) carried out an analysis based on the two-fluid formulation, in order to relate the fluctuations in bubble passage and the wall shear stress measurements.

Another approach consists in analysing the averaged velocity profiles, with and without bubbles. Marié (1987) proposes a model, assuming that the single-phase velocity profile is preserved in the wall region when considering a bubbly flow. Based on measurements in the boundary layer, it is shown that the viscous sub-layer and the logarithmic region remain constant in the presence of bubbles, only the wake function is affected. In that sense, the influence of the bubbles on the velocity profile near the wall is similar to the action of a grid on a single-phase turbulent boundary layer. The modified wake function is obtained by dimensional analysis, also using experimentally fitted coefficients, and the law for the wall shear stress ratio finally reads:

$\frac{\tau_{w}}{\tau_{w 0}} \approx 1+\frac{10}{3\left(1-\varepsilon_{a}\right)} \sqrt{k \varepsilon_{a}} \frac{U_{\infty}}{U_{\text {bulk }}}$

where $k$ is a constant in the order from 0.8 to $1.4, U_{\infty}$ is the terminal velocity of a bubble rising in stagnant water, and $U_{\text {bulk }}$ is the bulk velocity of the liquid (noted $U$ thereafter). According to Marié (1987), $k=1.1$ is the best fit for the measured data. $U_{\infty}$ can be obtained from experiments and from various correlations. For a bubble of diameter close to $3 \mathrm{~mm}, U_{\infty}$ is in the order of $0.25 \mathrm{~m} / \mathrm{s}$. So Eq. 10 becomes:

$\frac{\tau_{w}}{\tau_{w 0}} \approx M\left(\varepsilon_{a}, U\right)=1+\frac{10}{3\left(1-\varepsilon_{a}\right)} \sqrt{1.1 \varepsilon_{a}} \frac{0.25}{U}$

In Fig. 21, the measured wall shear stress ratio from our experiments is plotted against the corresponding value of $M$ from the measured $\varepsilon_{a} 2 \mathrm{~mm}$ from the wall and $U$, for a range of conditions for the liquid and gas superficial velocities.

Despite the assumptions made, particularly regarding the modification of the velocity profile due to the bubbles presence, $\tau_{w} / \tau_{w 0}$ and $M$ are in the same order of magnitude. There is a deviation between $\tau_{w} / \tau_{w 0}$ and $M$ as high as $70 \%$ in Fig. 21, especially for the larger values of $\tau_{w} / \tau_{w 0}$, but it can be seen that, using the variable $M$, all the data seem to follow a trend, regardless of the type of injection used. A more refined analysis of the data shows that the discrepancy between the measured wall shear stress and Eq. 11 increases with increasing gas superficial velocities, but is insensitive to the type of bubbles injected, small or large. In a subsequent work, Marié et al. (1997) consider the 


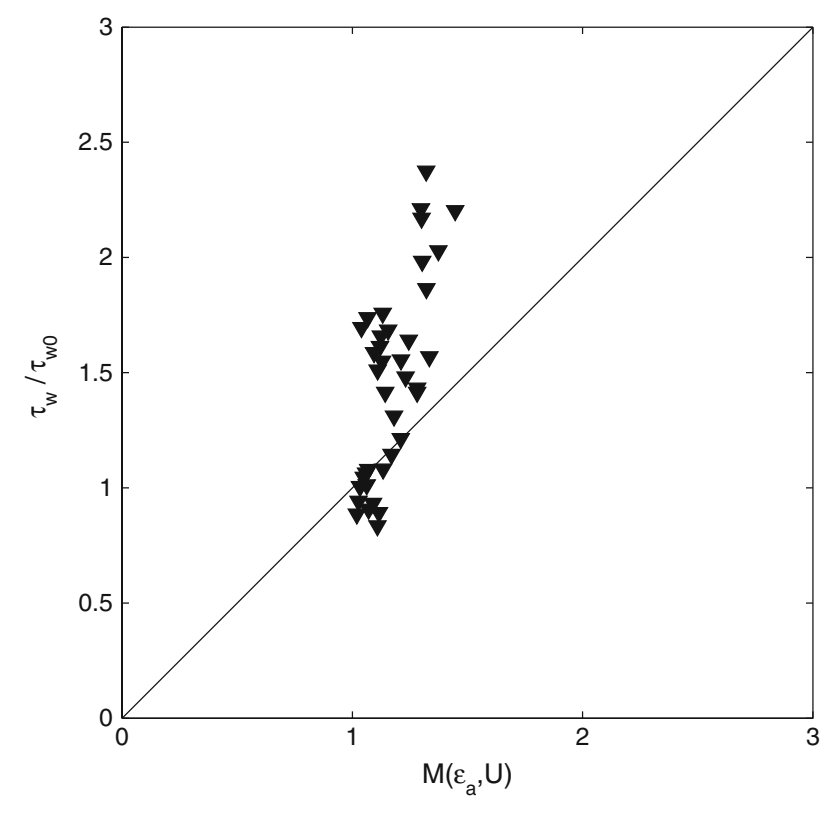

Fig. 21 Comparison of the measured wall shear stress ratio to the parameter $M$ of Eq. 11

logarithmic region to be affected by the bubbles as well, and a more complete relationship is derived, including the difference in void fraction between the wall region and the free stream region. However, for the results presented in Fig. 21, only the void fraction in the wall region was an available quantity. Besides, Eq. 11 brings out the influence of the mean local void fraction and liquid bulk velocity on the wall shear stress, through the parameter $M\left(\varepsilon_{a}, U\right)$, and allows for comparison with the available quantities in the present study.

\section{Summary and conclusion}

The influence of air bubbles in liquid on the wall shear stress has been investigated, for the case of a vertical bubbly flow. The motivation is to understand how bubble size can affect the pressure drop over a pipe for gas-lift application.

In order to answer these questions, dedicated measurements of the air bubbles characteristics in the vicinity of the the wall were performed. Standard measurement techniques included high-speed video recordings, pressure transducers, optical fibre probes. The wall shear stress induced by the bubbles in an air-water flow was studied using a hot film probe sensor. It was shown that this technique allows for the determination of the wall shear stress with a rather large uncertainty range, due to the calibration process and the change of the properties of the probe over a period of time. However, it provides useful information regarding the general evolution of the wall shear stress with flow rate changes, as well as for the temporal fluctuation of the stress. The liquid layer at the wall was measured using a conductive ring. This technique, based on conductivity measurement, showed reasonable accuracy after calibration in stagnant conditions.

For an air-water flow, the injection of small bubbles rather than large bubbles reduces the pressure drop by approximately $20 \%$ at most. The bubbles travelling close to the wall were shown to have a zigzagging motion, so the thickness of the liquid layer between the wall and the nearest bubbles oscillates in time and space. This effect is amplified for small injected bubbles because more bubbles are then available in the wall region. It was shown that the injection of small bubbles rather than large bubbles leads to lower bubble interarrival time, and accordingly, to a higher bubble passage frequency.

These mechanisms have implications on the wall shear stress. It was shown that the bubbles tend to increase it, when compared to the single phase case. So, no drag reduction occurs in a pipe flow using macro bubbles, in contradiction with what happens for micro bubbles of $0.1 \mathrm{~mm}$ on a flat plate. Also, the injection of small bubbles instead of large bubbles increases the wall shear stress even more, by $70 \%$ at most. This can be related to the previous observation that more bubbles travel in the wall region, when their initial size is small. Simultaneous measurements of the wall shear stress and the bubble passage supported this idea, by showing that any bubble travelling in the wall neighbourhood causes the shear stress at the wall to increase sharply (a wall shear stress spike). As more bubbles travel in the wall region, more spikes occur, and the mean stress increases.

Analytically, a decomposition of the turbulent stresses according to the fluctuating variables of the flow emphasised the relation between the wall shear stress and the bubble local volume fraction at the wall, but proved to be difficult to implement. Using a simple approach based on correlations, which assumes that the presence of the bubbles affects the mean transverse velocity profile in the wake region, it was possible to get qualitative agreement with the experimental data.

In a broader perspective, these results can be used to show that, in the presence of oil and water, the injection of small air bubbles for gas-lift application may not decrease the pressure drop at conditions where the oil-water mixture is very viscous. This is due to the predominance of the wall shear stress increase in such conditions, over the reduction of the gravitational pressure drop.

Open Access This article is distributed under the terms of the Creative Commons Attribution Noncommercial License which permits any noncommercial use, distribution, and reproduction in any medium, provided the original author(s) and source are credited. 


\section{References}

Belt R (2007) On the liquid film in inclined annular flow. $\mathrm{PhD}$ thesis, Delft University of Technology

van den Berg T, van Gils D, Lathrop D, Lohse D (2007) Bubbly turbulent drag reduction is a boundary layer effect. Phys Rev Lett 98:084501

Boyer C, Duquenne A, Wild G (2002) Measuring techniques in gasliquid and gas-liquid-solid reactors. Chem Eng Sci 57:31853215

Cartellier A, Achard J (1991) Local phase detection probes in fluid fluid 2-phase flows. Rev Sci Instrum 62(2):279-303

Descamps M, Oliemans R, Ooms G, Mudde R, Kusters R (2006) Influence of gas injection on phase inversion in an oil-water flow through a vertical tube. Int J Multiph Flow 32(3):311-322

Descamps M, Oliemans R, Ooms G, Mudde R (2007) Experimental investigation of three-phase flow in a vertical pipe: local characteristics of the gas phase for gas-lift conditions. Int $\mathrm{J}$ Multiph Flow 33(11):1205-1221

Ferrante A, Elghobashi S (2004) On the physical mechanisms of drag reduction in a spatially developing turbulent boundary layer laden with microbubbles. J Fluid Mech 503:345-355

Guet S (2004) Bubble size effect on the gas-lift technique. PhD thesis, Delft University of Technology

Guet S, Ooms G, Oliemans R, Mudde R (2003) Bubble injector effect on the gaslift efficiency. AIChE J 49(9):2242-2252

Hogsett S, Ishii M (1997) Local two-phase flow measurements using sensor techniques. Nucl Eng Des 175:15-24

Ioannou K, Nydal O, Angeli P (2005) Phase inversion in dispersed liquid-liquid flows. Exp Therm Fluid Sci 29:331-339

Julia J, Harteveld W, Mudde R, Van den Akker H (2005) On the accuracy of the void fraction measurements using optical probes in bubbly flows. Rev Sci Instrum 76(3):035103

Lance M, Bataille J (1991) Turbulence in the liquid phase of a uniform bubbly air-water flow. J Fluid Mech 222:95-118

Lu J, Fernandez A, Tryggvason G (2005) The effect of bubbles on the wall drag in a turbulent channel flow. Phys Fluids 17:095102
Madavan N, Deutsch S, Merkle C (1984) Reduction of turbulent skin friction by microbubbles. Phys Fluids 27(2):356-363

Magaud F, Souhar M, Wild G, Boisson N (2001) Experimental study of bubble column hydrodynamics. Chem Eng Sci 56:4597-4607

Marié J (1987) Modeling of the skin friction and heat transfer in turbulent two-component bubbly flows in pipe. Int $\mathrm{J}$ Multiph Flow 13(3):309-325

Marié J, Moursali E, Tran-Cong S (1997) Similarity law and turbulence intensity profiles in a bubbly boundary layer at low void fractions. Int J Multiph Flow 23(2):227-247

McCormick M, Bhattacharyya R (1973) Drag reduction of a submersible hull by electrolysis. Naval Eng J 85(2):11-16

Moursali E, Marié J, Bataille J (1995) An upward turbulent bubbly boundary layer along a vertical flat plate. Int J Multiph Flow 21(1):107-117

Murai Y, Oishi Y, Takeda Y, Yamamoto F (2006) Turbulent shear stress profiles in a bubbly channel flow assessed by particle tracking velocimetry. Exp Fluids 41:343-352

Murai Y, Fukuda H, Oishi Y, Kodama Y, Yamamoto F (2007) Skin friction reduction by large air bubbles in a horizontal channel flow. Int J Multiph Flow 33:147-163

Piela K, Delfos R, Ooms G, Westerweel J, Oliemans R, Mudde R (2006) Experimental investigation of phase inversion in an oilwater flow through a horizontal pipe loop. Int J Multiph Flow 32(9):1087-1099

Prasser H, Misawa M, Tiseanu I (2005) Comparison between wiremesh sensor and ultra-fast x-ray tomograph for an air-water flow in a vertical pipe. Flow Meas Instrum 16(2-3):73-83

Sato Y, Sadatomi M, Sekoguchi K (1981) Momentum and heat transfer in two-phase bubble flow-i. theory. Int J Multiph Flow 7(2): $167-177$

Tomiyama A, Tamai IH amd Zun, Hosokawa S (2002) Transverse migration of single bubbles in simple shear flow. Chem Eng Sci 57:1849-1858

Zaruba A, Lucas D, Prasser H, Höhne T (2007) Bubble-wall interactions in a vertical gas-liquid flow: bouncing, sliding and bubble deformations. Chem Eng Sci 62:1591-1605 